\title{
Purification and quantification of recombinant Epstein- Barr viral glycoproteins gp350/220 from Chinese hamster ovary cells
}

\author{
Martin Hessing*, Harm B. van Schijndel and Wout M. J. van Grunsven \\ Biotechnological Research Unit, Organon Teknika, Boseind 15, 5280 AB Boxtel (Netherlands)
}

\author{
Hans Wolf \\ Max von Pettenkofer Institute, Munich (Germany)
}

Jaap M. Middeldorp

Biotechnological Research Unit, Organon Teknika, Boseind 15, 5280 AB Boxtel (Netherlands)

\begin{abstract}
Truncated Epstein-Barr virus (EBV) membrane antigen gp350/220 (EBV-MA) lacking the membrane anchor was expressed and secreted into the medium of recombinant Chinese hamster ovary cells that had been cultured in Plasmapur hollow-fibre modules using defined serum-free medium. The EBV-MA in the medium was concentrated by $70 \%(\mathrm{w} / \mathrm{v})$ ammonium sulphate precipitation and subsequently purified by immunoaffinity chromatography using an anti-EBV-MA (EBV.0T6) monoclonal antibody (mAb) column. $\Lambda$ dsorbed antigen was eluted with $3 \mathrm{M} \mathrm{MgCl}_{2}$ in phosphate-buffered saline, concentrated by Mono $Q$ anion exchange chromatography and analysed by sodium dodecyl sulphate-polyacrylamide gel electrophoresis, silver staining and Western blotting using EBV-positive serum and anti-EBV-MA specific mAbs. Monospecific polyclonal rabbit antibodies against the purified EBV-MA were raised and purified by protein $\mathrm{G}$ affinity chromatography. For the measurement of EBV-MA antigen lcvels a sandwich cnzyme-linkcd immunosorbent assay using rabbit polyclonal antibodies and a horseradish peroxidase-conjugated anti-MA mAb was developed having a detection level of $10 \mathrm{ng} / \mathrm{ml}$.
\end{abstract}

\section{INTRODUCTION}

The Epstein-Barr virus (EBV) is a human lymphotropic and immunomodulating herpes virus which causes infectious mononucleosis upon primary infection in adults [1]. In addition, EBV is associated with a number of other human malignancies, e.g., nasopharyngeal carcinoma and Burkitt's lymphoma. Another result of primary infection is the presence in serum of antibodies to a number of EBV antigens, some of which are maintained at constant levels throughout life. One possibility for affecting the course of the various EBV-associated diseases is vaccination. At the moment the tar- get antigen for the development of an EBV vaccine is the EBV membrane antigen (EBV-MA) gp350/ 220 complex [2-4], which is found both on the envelopes of viral particles [5] and on the surface of EBV producer cells. In addition, EBV-MA may be a useful antigen in diagnostic assays.

EBV-MA consists of the glycoproteins gp 350 and gp220 that are encoded by the same gene, which has been mapped to the BamHI L DNA fragment of the B95-8 genome [6]. The mRNA of gp220 arises by internal splicing of the mRNA of gp350 in such a manner that the same open reading frame (BLLF1) is maintained [6]. EBV-MA is important for virion binding to human $B$ lymphocytes via its specific in- 
teraction with the complement receptor 2 (CR2) [7] and is also an efficient activator of the alternative pathway of complement [8]. The gp 350 primary sequence consists of 907 amino acids and includes 36 potential signals for $\mathrm{N}$-linked glycosylation, a single hydrophobic transmembrane domain and a short $\mathrm{C}$-terminal domain. More than half of the relative molecular mass $\left(M_{\mathrm{r}}\right)$ is contributed by glycosyl residues. EBV-MA is synthesized in the endoplasmic reticulum, undergoes rapid cotranslational N-linked glycosylation and is transported to the Golgi, where high-mannose $\mathrm{N}$-linked oligosaccharides are trimmed and complex $\mathrm{N}$ - and $\mathrm{O}$-linked oligosaccharides are added [9-13].

Several monoclonal antibodies (mAbs) against EBV-MA have been prepared and it has been reported by different groups that such antibodies mediate virus neutralization, antibody-dependent cellular cytotoxicity, complement-dependent cytotoxicity and inhibition of virus release [14-18]. It should be emphasized that the different epitopes of the EBV-MA complex play variable roles in virus neutralization, virus binding to target cell receptors and virus penetration [19]. Recent data suggest that only onc epitope, located in the $\mathrm{N}$-terminal region of EBV-MA, is involved in EBV neutralization and binding to target cell receptors $[9,20]$.

Production of native EBV-MA for vaccination or diagnostic purposes is hampered by the lack of a suitable high-level expression system [3,4]. Recombinant EBV-MA has been produced in bacteria [21], yeast [22], mouse L cells [29], rat pituitary GH3 cells [23], Vero cells [23] and Chinese hamster ovary (CHO) cells [24] and has been expressed via different viral vectors $[3,25,26]$. Although cell-specific post-translational modifications critically influence the antigenic presentation of EBV-MA, all mammalian cell-derived versions of EBV-MA were found capable of inducing EBV-specific neutralizing antibodies [2]. As expressing levels of recombinant EBV-MA were low, suggesting that the protein is toxic for eukaryotic cells, truncated forms of EBV-MA lacking the membrane anchor have been expressed $[2,27,28]$. Truncated EBV-MA was sccreted into the medium of transformed cells in culture. Determination of truncated EBV-MA secretion was difficult and for $\mathrm{CHO}$ cells has been estimated from Coomassie Brilliant Blue-stained gels to be in the range $1-10 \mu \mathrm{g}$ per $10^{6}$ cells per day [28].
In this paper we describe the culturing and purification of recombinant truncated EBV-MA from CHO cells [28] by $\mathrm{mAb}$-based affinity chromatography and the subsequent development of an enzymelinked immunosorbent assay (ELISA) procedure for the measurement of EBV-MA antigen levels.

\section{EXPERIMENTAL}

\section{Materials}

Protein $G$-Sepharose FF, a Mono $Q$ column and cyanogenbromide-activated Sepharose were obtained from Pharmacia LKB Biotechnology (Uppsala, Sweden). Prestained molecular mass markers and $\mathrm{N}, \mathrm{N}^{\prime}$-diallyltartardiamide (DATD) were obtained from Bio-Rad Labs. (Richmond, CA, USA). All culture plastics were obtained from Costar (Badhoevedorp, Netherlands). Culture media were based on HAM's F12--Dulbecco's modified Eagle's medium (DMEM) (1:1) from Gibco (Paisley, UK) and were occasionally supplemented with $10 \%$ foetal calf serum (Bocknek, Canada). Plasmapur hollow-fibre modules and bovine serum albumin (BSA) were from Organon Teknika (Boxtel, Netherlands). Horseradish peroxidase (HRP) was purchased from Sigma (St. Louis, MO, USA). All other chemicals were of the highest grade available.

\section{Antibodies}

Polyclonal antibodies against EBV-MA were obtained from rabbits by multiple subcutaneous injections of $0.2 \mathrm{mg}$ of purified EBV-M $\Lambda$ in Freund's complete adjuvant and after 2, 4 and 6 weeks they were boosted with the same amount of antigen in incomplete adjuvant. Anti-EBV-MA specific $m A$ bs (EBV.OT2, -3, -6 and -7) were prepared as will be described elsewhere. MAb EBV.OTIC was generously provided by Dr. D. Thorley-Lawson. Hybridomas were cultured in serum-free medium using Plasmapur hollow-fibre bioreactors [29]. Supernatants from the extra-capillary compartment were harvested, centrifuged, divided into aliquots and stored at $-20^{\circ} \mathrm{C}$. The total mouse immunoglobulin $\mathrm{G}$ (IgG) concentration in samples of hybridoma cultures was determined using the Sol Particle Immunoassay [30]. IgGs were isolated on protein GSepharose FF according to the instructions of the manufacturer. The concentration of the purified monoclonal antibodies was determined by measur- 
ing the absorbance at $280 \mathrm{~nm}$ using a molar absorptivity $(1 \%, 1 \mathrm{~cm})$ of $14.3[31]$.

\section{Human sera}

EBV-seropositive sera were obtained from healthy laboratory volunteers and commercial blood donor populations. Sera from acutely infected patients were provided by Dr. G. Weers-Pothof (Department of Medical Microbiology, University Hospital, Nijmegen, Netherlands).

\section{Purification of $E B V-M A$}

Culturing of $\mathrm{CHO}$ cells secreting truncated EBVMA was performed in roller bottles under methotrexate selection [28]. When the cells were in the logarithmic phase they were inoculated in the extracapillary compartment of hollow-fibre bioreactors and cultured without methotrexate essentially as described above for the hybridomas [29].

The EBV-MA in the extra-capillary harvest fluid of the CHO cells was precipitated with $70 \%(\mathrm{w} / \mathrm{v})$ ammonium sulphate and dissolved in phosphatebuffered saline (PBS) (pH 7.4) and dialysed against the same buffer. Then EBV-MA was purified by monoclonal anti-EBV-MA antibody affinity chromatography. For this mAb EBV.OT6 was coupled to cyanogen bromide-activated Sepharose 4B (10 $\mathrm{mg} / \mathrm{ml}$ ) according to the manufacturer's instructions, and the gel was packed into a column $(15 \times 1$ $\mathrm{cm}$ I.D.). EBV-MA-containing dialysate was passed through a Millex-HA $0.22-\mu \mathrm{m}$ filter (Millipore) and subsequently applied to the column, which had been equilibrated in PBS ( $\mathrm{pH} 7.4)(10 \mathrm{ml} / \mathrm{h})$. After extensive washing with the equilibration buffer, adsorbed EBV-MA was eluted with $3 \mathrm{M} \mathrm{MgCl}_{2}$ in PBS ( $\mathrm{pH}$ 7.4). The eluted protein fractions were pooled and dialysed against $50 \mathrm{mM}$ Tris- $\mathrm{HCl}-50$ $\mathrm{m} M \mathrm{NaCl}(\mathrm{pH}$ 7.4). Concentration of EBV-MA and removal of traces of IgG leakage from the affinity matrix was performed with Mono $Q$ anion-exchange chromatography using fast protein liquid chromatographic (FPLC) equipment (Pharmacia) with a linear gradient of $\mathrm{NaCl}(50-500 \mathrm{mM} \mathrm{NaCl}$, $20 \mathrm{ml}$ ) with a flow-rate of $60 \mathrm{ml} / \mathrm{h}$ and a fraction size of $1 \mathrm{ml}$. Protein concentrations were determined by the bicinchoninic acid (BCA) protein assay (Pierce, Rockford, IL, USA) using BSA as reference.

\section{Electrophoretic and immunochemical techniques}

Sodium dodecyl sulphate-polyacrylamide gel electrophoresis (SDS-PAGE) was performed under non-reducing and reducing conditions on $6 \%$ slab gels with DATD as cross-linker using the Mini-Protean II system (Bio-Rad Labs.) or on 4-15\% gradient gels using the Phast system (Pharmacia) essentially according to Laemmli [32]. After electrophoresis, proteins were transferred to Immobilon membranes (Millipore) essentially as described [33]. The membranes were blocked with $5 \%(\mathrm{v} / \mathrm{v})$ horse serum, 4\% (w/v) non-fat dry milk [34] in PBS, incubated with monoclonal or polyclonal antibodies against EBV-MA and visualized with peroxidaseconjugated antiserum using 4-chloro-1-naphthol as substrate.

The gels were stained with Coomassie Brilliant Blue R-250 or with an ammonical silver staining procedure essentially according to Morrisey [35]. Reduction was performed by incubating the samples for $5 \mathrm{~min}$ at $90^{\circ} \mathrm{C}$ with $5 \%(\mathrm{v} / \mathrm{v}) 2$-mercaptoethanol-10 mM Tris-HCl-2\% (w/v) SDS-0.01\% (w/ v) bromophenol blue-10\% (v/v) glycerol (pH 6.8).

\section{ELISA for the measurement of EBV-MA}

A two-stage ELISA was developed using polyclonal anti-EBV-MA IgG and an HRP-conjugated anti-EBV-MA mAb. Purified polyclonal anti-EBVMA antibodies ( $5 \mu \mathrm{g} / \mathrm{ml}, 50 \mathrm{mM} \mathrm{NaHCO}_{3}, \mathrm{pH}$ 9.6) were coated overnight on 96-well microtitre plates (Greiner) at $4^{\circ} \mathrm{C}$. After removal of unbound EBVMA antibodies by washing with PBS-Tween-20, the plates were blocked with $3 \%(w / v)$ BSA in PBS for $30 \mathrm{~min}$ and subsequently incubated with dilutions of purified EBV-MA [in 5\% (v/v) normal goat serum- $0.05 \%(\mathrm{v} / \mathrm{v})$ Tween-20 in PBS] at room temperature for $2 \mathrm{~h}$. After washing, HRP-conjugated mAb (EBV.OT6) was applied and incubated for 1 $h$. Bound conjugated antibody was developed for peroxidase activity using the substrate $3,3^{\prime}, 5,5^{\prime}$-tetramethylbenzidine. The absorbance at $450 \mathrm{~nm}$ was read against a blank using an Anthos 2001 reader. MAb EBV.OT6 was conjugated with HRP (Type VI) (Sigma) by periodate oxidation. 


\section{RESULTS}

Characterization of monoclonal antibodies against $E B V-M A$

For the development of an EBV-MA specific immunoaffinity purification process, five mouse mAbs against EBV-MA were obtained and characterized by Western blotting and ELISA. The mAbs EBV.OTIC and EBV.OT6 demonstrated a strong positive reactivity with EBV-MA in ELISA (Fig. 1), whereas the mAb's EBV.OT 2, 3 and 7 showed minor reactivity. As only $\mathrm{mAb}$ EBV.OT6 was reactive in Western blotting (Fig. 2), this $\mathrm{mAb}$ was selected for purification purposes.

\section{Purification of $E B V-M A$}

Recombinant truncated EBV-MA secreting $\mathrm{CHO}$ cells were cultured in Plasmapur hollow-fibre modules using defined serum-free medium. Fig. 3 shows a Western blot analysis of supernatants derived from the cell line at several days of culture using an anti-EBV positive human serum. Owing to extensive glycosylation EBV-MA appears as diffuse bands.

The EBV-MA was purified from the medium of CHO cells by ammonium sulphate precipitation, monoclonal anti-EBV-MA antibody affinity and Mono $Q$ anion-exchange chromatography (not shown), and subsequently analysed by SDS-PAGE

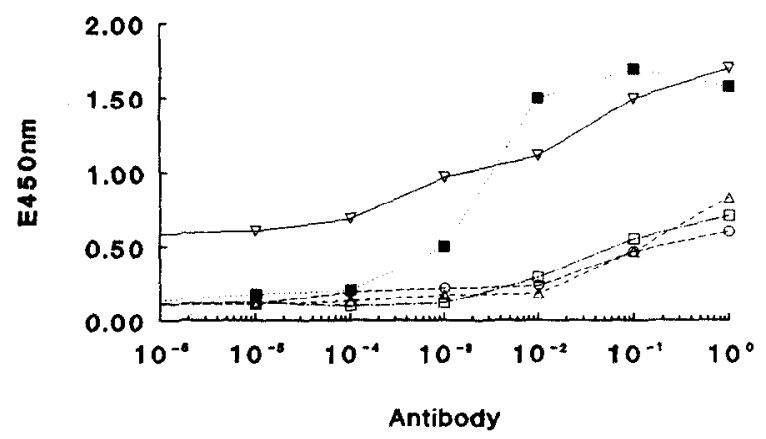

Fig. 1. Reactivity of mAbs with recombinant truncated EBVMA. The binding activities of $(\nabla) \mathrm{mAb}$ EBV.OT1C, $(\Delta)-2,(0)$ $-3,(\mathbf{a})-6$ and $(\mathrm{G})-7$ to recombinant EBV-MA were determined by ELISA. Microtitre wells were coated with 1:100 dilutions of ammonium sulphate-concentrated EBV-MA preparations and incubated with various concentrations of each $\mathrm{mAb}$. Bound antibody was detected with peroxidase-conjugated sheep anti-mouse $\mathrm{IgG}$ and $3,3^{\prime}, 5,5^{\prime}$-tetramethylbenzidine.

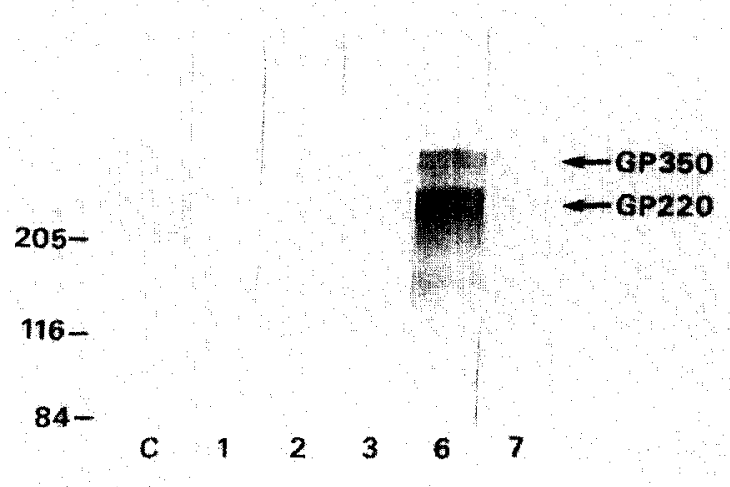

Fig. 2. Western blot analysis of the reactivity of ditferent antiEBV-MA mAbs with recombinant EBV-MA. EBV-MA was subjected to $6 \%$ SDS-PAGE and the gels were transferred to Immobilon membranes. The membranes were incubated with the $\mathrm{mAbs}$ and visualized with peroxidase-conjugated antiserum. $M_{\mathrm{r}}$ standards (kilodallons) and a positive control (C) with EBVpositive human serum are included.

and Western blotting. The purified EBV-MA demonstrated a characteristic doublet of gp 350 and gp220 on a silver-stained SDS polyacrylamide (PAA) slab gel and was devoid of low- $M_{\mathrm{r}}$ contaminants (Fig. 4a). Reduced and non-reduced purified EBV-MA showed similar electrophoretic mobilities (not shown). Fig. $4 b$ shows the positive reactivity of the purified EBV-MA with the HRP-labelled anti-

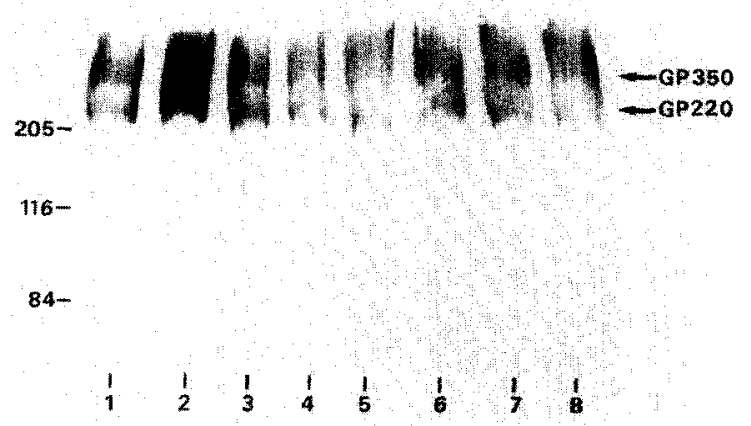

Fig. 3. Western blot analysis of culture supernatants from CHO cells secreting truncated EBV-MA [28]. Culture supernatants from subsequent passages were run on a $6 \%$ SDS-PAA gel and transferred to Immobilon membranes. The membranes were developed with a 1:1000 dilution of an anti-EBV positive human serum and HRP-labelled anti-human antiserum. 


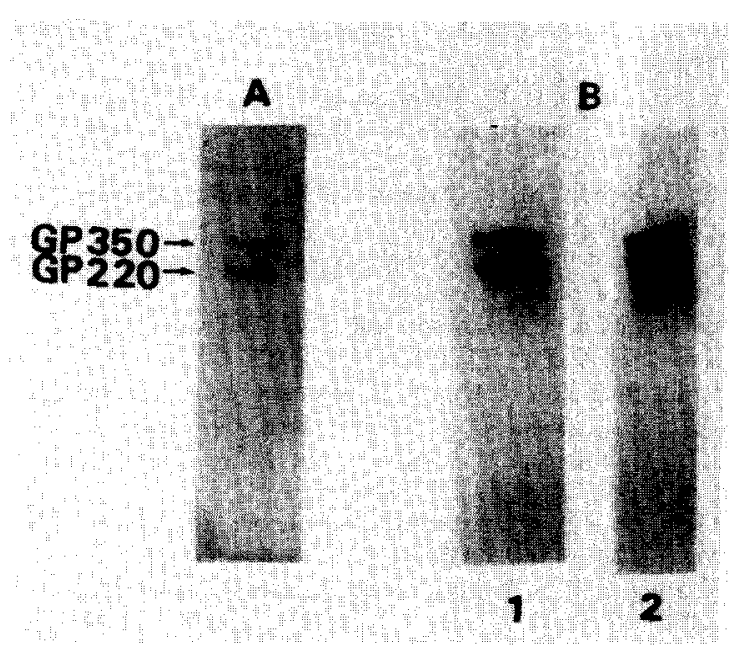

Fig. 4. SDS-PAGF of immunopurified recombinant EBV-MA visualized by (A) silver staining and (B) immunoblotting. Reduced EBV-MA was subjected to 6\% SDS-PAGE and the gels were stained with silver or transferred to Immobilon membranes. The membranes were incubated with the mAb EBV.OT6 (lane 1) or human serum (lane 2) and visualized with peroxidase-conjugated antiserum. $M_{\mathrm{r}}$ standards are indicated (kilodalton).

EBV-MA mAb EBV.OT6 and an EBV-positive human serum in Western blotting analysis.

\section{ELISA for EBV-MA}

A two-stage EBV-MA ELISA was developed using immunopurified polyclonal anti-EBV-MA IgG, coated to 96-well microtitre plates, in the solid phase and peroxidase-conjugated monoclonal antiEBV-MA IgG in the liquid phase. Fig. 5 shows a

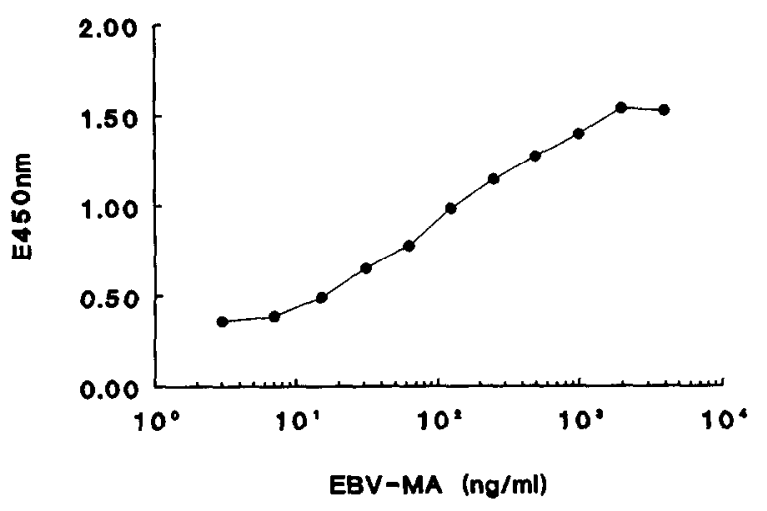

Fig. 5. Dose-response curve of serially diluted EBV-MA in ELISA.

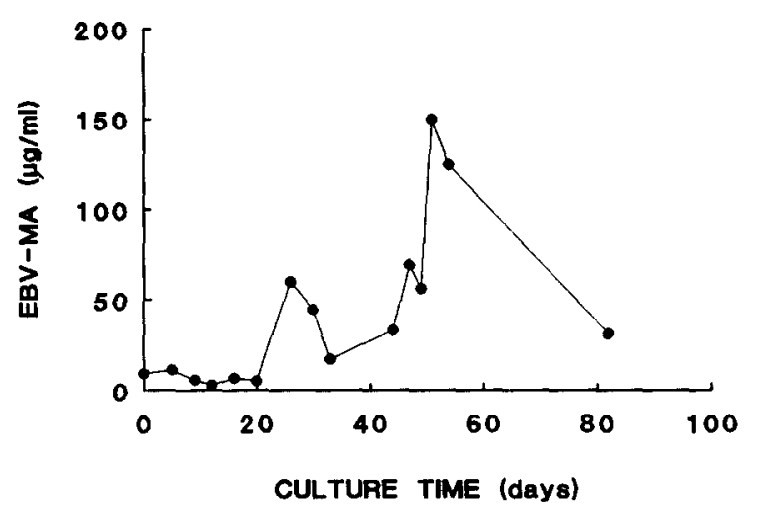

Fig. 6. Long-term cultivation of $\mathrm{CHO}$ cells secreting truncated EBV-MA in hollow-fibre modules. Monitoring of EBV-MA production was performed during the culture period as measured by ELISA.

representative dose-response curve for the EBVMA ELISA. A significant difference in absorbance as compared with buffer alone corresponded to a detection limit of about $10 \mathrm{ng} / \mathrm{ml}$.

The EBV-MA production during the cell culture period of the CHO cells was monitored by this procedure, as shown in Fig. 6. Starting at day 0 a concentration of $9.3 \mu \mathrm{g} / \mathrm{ml}$ of EBV-MA (in roller bottle culture) was obtained. The concentration of EBVMA in the medium of the hollow-fibre modules increased slowly up to 20 days, followed by a period of decline. This decline was caused by the change of the culture in the extra-capillary compartment to a serum-free medium. Subsequently, a period of exponential increase of EBV-MA production was observed that reached its maximum $(150 \mu \mathrm{g} / \mathrm{ml})$ at day 50 which was followed by a period of decline until the end of the culture.

\section{DISCUSSION}

Truncated recombinant EBV-MA derived from CHO cells was purified by ammonium sulphate precipitation and anti-EBV-MA $\mathrm{mAb}$ affinity and anion exchange chromatography. Both gp350 and gp220 species were obtained, which is in agreement with previously reported results $[24,28]$. The observed $M_{\mathrm{r}}$ values suggest a close to natural glycosylation, which is relevant for vaccination purposes $[2-4]$. However, the nature of the $\mathrm{N}$ - and O-linked 
oligosaccharides attached to the recombinant EBVMA remains to be characterized. The recombinant CHO cell line showed stable production characteristics over several weeks under serum-free culture conditions without methotrexate selection. No dramatic changes were observed in either production level (about $75 \mu \mathrm{g} / \mathrm{ml}$ per day) or the nature of the protein species produced. Hence the procedure described in this paper allows for the development of a simple, efficient and economical system for the large-scale production of EBV-MA.

The purified EBV-MA may be used for a possible EBV subunit vaccine or could be used as antigen for early diagnosis, thereby providing an efficient approach to the control of EBV-related diseases. The EBV-MA itself can be used for immunological studies or used in ELISAs for determining antibody to EBV-MA or used in receptor binding studies [7]. In this study, we developed a monoclonal antibody-based ELISA for the determination of EBVMA in cell culture. The assay was sensitive, accurate and specific with a limit of detection of EBVMA antigen of about $10 \mathrm{ng} / \mathrm{ml}$. This assay may be generally useful in the determination of EBV-MA derived from natural or recombinant sources.

\section{REFERENCES}

1 K. Nilsson, G. Klein, W. Henle and G. Henle, Int. J. Cancer, 8 (1971) 443-450

2 E. A. Emini, W. A. Schleif, M. C. Armstrong, M. Silberklang, L. D. Schlutz, D. Lehman, R. Z. Maigetter, L. F. Qualtiere, G. R. Pearson and R. W. Ellis, Virology, 166 (1988) 387-393

3 A. J. Morgan, M. Mackett, S. Finerty, J. R. Arrand, F. Scullion and M. A. Epstain, J. Med. Virol., 25 (1988) 189-195.

4 A. J. Morgan, A. C. Allison, S. Finerty, N. E. Byars and M. A. Epstein, J. Med. Virol., 29 (1989) 74-78.

5 G. R. Pearson and L. F. Qualtiere, J. Virol, 28 (1978) 344 351.

$6 \mathrm{M}$. Hummel, D. A. Thorley-Lawson and E. Kieff, J. Virol, 49 (1984) 413-417.

7 J. Tanner, J. Weis, D. Fearon. Y. Whang and E. Kieff. Cell, 50 (1987) 203-213.

8 C. Mold, B. M. Bradt, G. R. Nemerow and N. K. Cooper, $J$. Imnunol., 140 (1988) 3867-3874.

9 G. R. Nemerow, R. A. Houghten, M. D. Moore and N. R. Cooper. Cell. 56 (1989) 369-377.
10 C. M. Edson and D. A. Thorley-Lawson. J. Virol. 46 (1983) 547-556.

11 F. Serafini-Cessi, N. Malagolini, M. Nanni, F. Dallolio, G. Campadelli-Fiume, J. Tanner and E. Kieff, Virology, 170 (1989) $1-10$

12 B. C. Strnad, M. R. Adams and H. Rabin, Virology, 127 (1983) $168-176$

13 J. Tanner, Y. Whang, J. Sample, A. Sears and E. Kieff. $J$. Virol. 62 (1988) $4452-4464$.

14 G. Hoffman, S. Lazarowitz and S. D. Hayward. Proc. Natl. Acad. Sci. U.S.A., 77 (1980) 2979-2983.

15 L. F. Qualtiere, R. Chase, B. Vroman and G. R. Pearson, Proc. Narl. Acad. Sci. U.S.A., 79 (1982) 616-620.

16 L. F. Qualtierre, J. F. Decoteau and M. H. Nasr-El-Din, $J$. Gen. Virol., 68 (1987) 535-543.

17 D. A. Thorley-Lawson and K. Geillinger. Proc. Narl. Acad. Sci. U.S.A., 77 (1980) 5307-5311.

18 T. Sairenji, P. S. Reisert and R. C. Spiro, J. Exp. Med., 161 (1985) 109\%-1111.

19 M. A. Epstein, B. J. Randle and S. Finerty. Clin. Exp. Immu nol. 63 (1986) 485490 .

20 R. Stocco, G. Sauvageau, I. Stefanescu and J. Menezes, Intervirology, 31 (1990) 295-300.

21 C. Beisel, J. Tanner, T. Matsuo, D. Thorley-Lawson, F. Kezdy and E. Kief, J. Virol., 54 (1985) 665-674.

22 L. D. Schultz, J. Tanner, K. Hofmann, K. J. Emini. J. H. Condra, R. E. Jones. E. Kieff and R. W. Ellis, Gene, 54 (1987) $113-123$

23 Y. Whang, M. Silberkalng, A. Morgan, S. Munski, A. Lenny and E. Kieff, J. Virol., 61 (1987) 1796-1807.

24 M. Motz, G. Deby. W. Jilg and H. Wolf, Gene, 44 (1986) $353-359$.

25 R. S. Lowe, P. M. Keller, B. J. Keeck, A. J. Davidson, Y. Whang. A. J. Morgan. E. Kieff and R. W. Ellis, Proc. Natl. Acad. Sci. U.S.A., 84 (1987) 3896-3900.

26 M. Mackett and J. R. Arrand, EMBO J., 4 (1985) 3229-3234.

27 M. Conway. A. Morgan and M. Mackett. J. Gin. Virol.. 70 (1989) 729-734

28 M. Motz. G. Deby and H. Wolf, Gene, 58 (1987) 149154

29 O. T. Schonherr. P. T. J. A. van Gelder, P. J. van Hees, A. M. J. M. van Os and H. W. M. Roelofs, Dev, Biol. Stand., 66 (1987) $211-220$.

30 J. H. W. Leuvering, B. C. Goverde, P. J. H. M. Thal and A. H. W. M. Schuurs, J. Immunol. Methods, 60 (1983) 9-23.

31 J. R. Little and H. Donahue, Merhods Immonol. Immunochem., 2 (1968) 343-368.

32 U. K. Laemmli, Nature (London), 227 (1970) 680-685.

33 H. Towbin. Th. Staehelin and J. Gordon. Proc. Natl. Acad. Sci. U.S.A., 76 (1979) $4350-4354$.

34 D. A. Johnson, J. W. Gautsch, J. R. Sportman and J. H. Elder, Gene Anal. Terh. I (1984) 3-8.

35 J. H. Morrisey, Anal. Biochem.. 117 (1981) 307-310. 